\title{
Correction to: Fiscal policy and economic growth: some evidence from China
}

\author{
Jungsuk Kim ${ }^{1}$ (1) Mengxi Wang ${ }^{1}$. Donghyun Park ${ }^{1}$. \\ Cynthia Castillejos Petalcorin ${ }^{1}$
}

Published online: 2 July 2021

(c) Kiel Institute 2021

\section{Correction to: Review of World Economics https://doi.org/10.1007/s10290-021-00414-5}

In the original publication of the article, the email addresses and affiliations of the second, third and fourth authors, Mengxi Wang, Donghyun Park and Cynthia Castillejos Petalcorin.were incorrect. The corrected email address and affiliation is as below.

First, the email addresses are changed to:

“mengxi.wang@samsung.com” for Mengxi Wang “dpark@adb.org” for Donghyun Park “cpetalcorin@adb.org” for Cynthia Castillejos Petalcorin.

Second, the affiliations for Mengxi Wang, Donghyun Park and Cynthia Castillejos Petalcorin are changed from "Sejong University, Seoul, Republic of Korea" to "Samsung China Economic Institute, 5/F China Merchants Tower No.118, Jian Guo Lu, Chao Yang District Beijing. China 100,022” for Mengxi Wang

The original article can be found online at https://doi.org/10.1007/s10290-021-00414-5.

Jungsuk Kim

js_kim@sejong.ac.kr

Mengxi Wang

mengxi.wang@samsung.com

Donghyun Park

dpark@adb.org

Cynthia Castillejos Petalcorin cpetalcorin@adb.org

1 Sejong University, Seoul, Republic of Korea 
"Principal Economist, Asian Development Bank, Economic Research and Regional Cooperation Department 6 ADB Avenue, Mandaluyong City, Metro Manila 1550, Philippines" for Donghyun Park

"Senior Economics Officer, Asian Development Bank, Economic Research and Regional Cooperation Department 6 ADB Avenue, Mandaluyong City, Metro Manila 1550, Philippines" for Cynthia Castillejos Petalcorin.

Publisher's Note Springer Nature remains neutral with regard to jurisdictional claims in published maps and institutional affiliations. 